American Journal of Applied Sciences 10 (10): 1270-1279, 2013

ISSN: 1546-9239

(C) 2013 Dauqan and Abdullah, This open access article is distributed under a Creative Commons Attribution

(CC-BY) 3.0 license

doi:10.3844/ajassp.2013.1270.1279 Published Online 10 (10) 2013 (http://www.thescipub.com/ajas.toc)

\title{
Utilization of Gum Arabic for Industries and Human Health
}

\author{
Eqbal Dauqan and Aminah Abdullah \\ School of Chemical Sciences and Food Technology, \\ Faculty of Science and Technology, \\ University Kebangsaan Malaysia, 43600 Bangi Selangor, Malaysia
}

Received 2012-11-07, Revised 2013-06-04; Accepted 2013-09-03

\begin{abstract}
Gum Arabic, a natural polysaccharide derived from exudates of Acacia senegal and Acacia seyal trees, is a commonly used food hydrocolloid. The highlight of this study was to review the utilization of gum Arabic for industries and human health. Gum Arabic has a unique combination of excellent emulsifying properties and low solution viscosity. These properties make gum Arabic very useful in several industries but especially in the food industry where it is used as a flavor and stabilizer of citrus oil emulsion concentrates in soft drinks.
\end{abstract}

Keywords: Gum Arabic, Acacia Senegal, Acacia Seyal

\section{INTRODUCTION}

Gum Arabic (GA) is edible, dried, gummy exudates from the stems and branches of Acacia senegal and Acacia seyal that is rich in non-viscous soluble fiber (Azeez, 2005; Badreldin et al., 2008; Abdul-Hadi et al., 2010). These trees are abundant in the central Sudan, central Africa and in West Africa. Gum Arabic is commonly used in the pharmaceutical and food industres as emulsifier and stabilizer as suspending agent for insoluble drugs (AbdulHadi et al., 2010; Lelon et al., 2010). Figure 1 shows the collection gum Arabic from low branches of acacia tree.

The chemical composition of GA can vary with its source, the age of the trees from which it was obtained, climatic conditions and soil environment. Gum Arabic is a branched-chain, complex polysaccharide, either neutral or slightly acidic, found as mixed calcium, magnesium and potassium salt of a polysaccharidic acid (Arabic acid) (Badreldin et al., 2008; Abdul-Hadi et al., 2010). The major amino acids present in the protein of an ArabinoGalactan (AG) and an Arabinogalactan-Protein Complex (AGP) were hydroxyproline, serine and proline, whereas in GlycoProtein (GP), aspartic acid was the most abundant (Badreldin et al., 2008).
Gum Arabic is primarily indigestible to both humans and animals. It is not degraded in the small intestine, but fermented in the large intestine by microorganisms to short-chain fatty acids, particularly propionic acid. Despite the fact that GA is widely used as a vehicle for drugs in experimental physiological and pharmacological experiments and is assumed to be an "inert" substance, some recent reports have claimed that GA possesses antioxidant, nephroprotectant and other effects (Badreldin et al., 2008).

Among all the types of gums marketed worldwide, Gum Arabic is certainly the most well known and the most in demand both at the levels of the producing regions and internationally. This often leads to a depreciation of offers because some suppliers mix in other elements into the product in order to fulfill their obligations. It also resulted in the over-exploitation of resources as producers seek to increase the availability of gum Arabic (Lelon et al., 2010).

Gum Arabic is rich in dietary fiber that is derived from dried exudates of $A$. senegal (Nasir et al., 2008), It contains a high molecular weight (lipoprotein) heterogeneous gum polysaccharides (Abd-Razig et al., 2010).

Corresponding Author: Eqbal Dauqan, School of Chemical Sciences and Food Technology, Faculty of Science and Technology, University Kebangsaan Malaysia, 43600 Bangi Selangor, Malaysia 


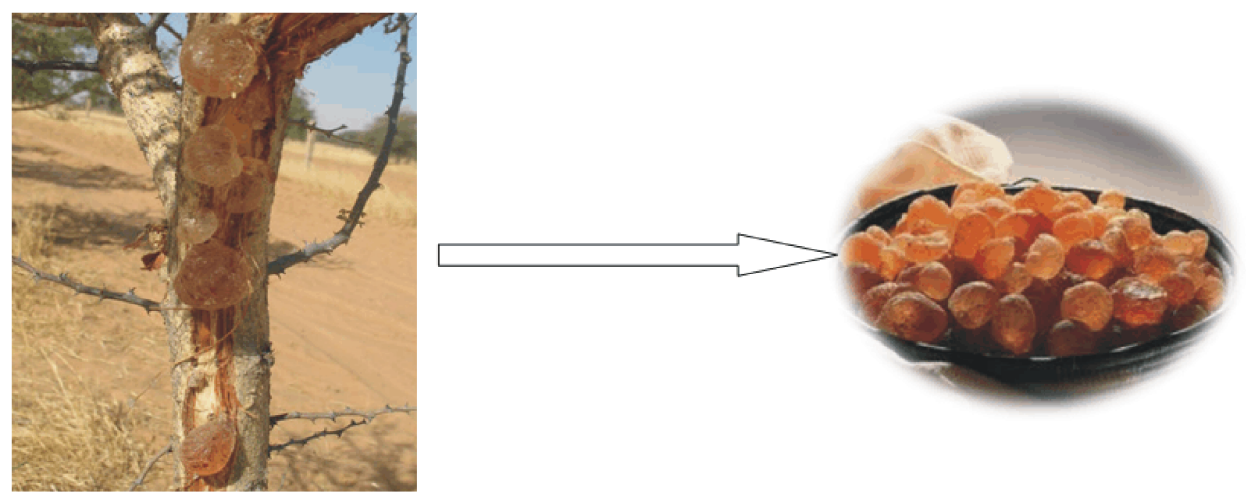

Fig. 1. Collecting gum Arabic from low branches of acacia tree

\subsection{History and Origins of Gum Arabic}

Gum Arabic is certainly the most ancient and the most well known of all gum types. The term 'gum Arabic' was coined by European merchants who imported it from Arab ports such as Jeddah and Alexandria. Egyptians referred to it as 'kami' and allegedly used it from the third dynasty onwards (around $2650 \mathrm{BC}$ ) to secure bandages around mummies. This gum was supposedly also used to fix pigments into hieroglyphic paintings. According to a Sudanese researcher, the word 'mana' (manna) mentioned in the Koran (Surah Al baquarah) as the best food available to man is, in fact, a direct reference to gum Arabic. The word 'mana' seemingly also refers to gum Arabic in the Torah where it is described as an essential food and designated by Moses to the Israelis as God-given bread. There are close to 900 acacia species capable of producing gum. These are primarily located in tropical climates, with about 130 of them located specifically on the African continent (ITC, 2008).

Africa, therefore, quickly became the major site of the production of gum; this is the reason why it is also referred to as 'senegal gum'. Gum is essentially the secretion of several acacia (leguminous) trees. Acacia gum species, of which there are up to seventeen, produce acacia gum of varying quality and quantity. Interestingly, close to $80 \%$ of gum Arabic is produced by the $A$. senegal (in Sudan). The remainder is produced either by the Acacia laeta or the $A$. seyal, with each species contributing $10 \%$ of the total supply of gum. The gum produced by the $A$. senegal is commonly referred to as "hard gum" and the gum from A. seyal, as "flaky gum" (Forestry Department, 1995). Gums obtained from other acacia species and occasionally from Albizia and Combretum, are also traded as "gum Arabic". Current regulation surrounding gum Arabic does not distinguish between gum obtained from Acacia senegal and A. seyal. (ITC, 2008).

\subsection{For Sudanese Exports, the Distinction is Quite Clear}

Gum from $A$. senegal is sold under the name "hashab gum" while gum from $A$. seyal is sold as "talha gum". In Zimbabwe, the gum traded locally as gum Arabic comes from Acacia karoo. However, synthetic substitutes, namely "modified starches" such as xanthan and gellane, are rapidly replacing gum Arabic as dietary hydrocolloides. Gum Arabic is traditionally defined as a 'substance, which exudes from $A$. Senegal or related species'. This definition encompasses a variety of species, which, from a taxonomy point of view, are not related. To date, though, only the gum from $A$. senegal has been effectively demonstrated as an innocuous food additive (ITC, 2008).

\subsection{Structure of Gum Arabic}

Gum Arabic, a natural composite polysaccharide derived from exudates of $A$. senegal and $A$. seyal trees, is one of the most commonly used food hydrocolloids. Gum Arabic serves as a very efficient emulsifier and a long-term stabilizer in food and cosmetic products containing oil-water interfaces. Gum Arabic is recognized by many researchers that GA consists of mainly three fractions (Yael et al., 2006). Figure 2 shows the structure of gum Arabic:

- The major fraction is a highly branched polysaccharide consisting of galactose backbone with linked branches of arabinose and rhamnose, which terminate in glucuronic acid found in nature as magnesium, potassium and calcium salt 


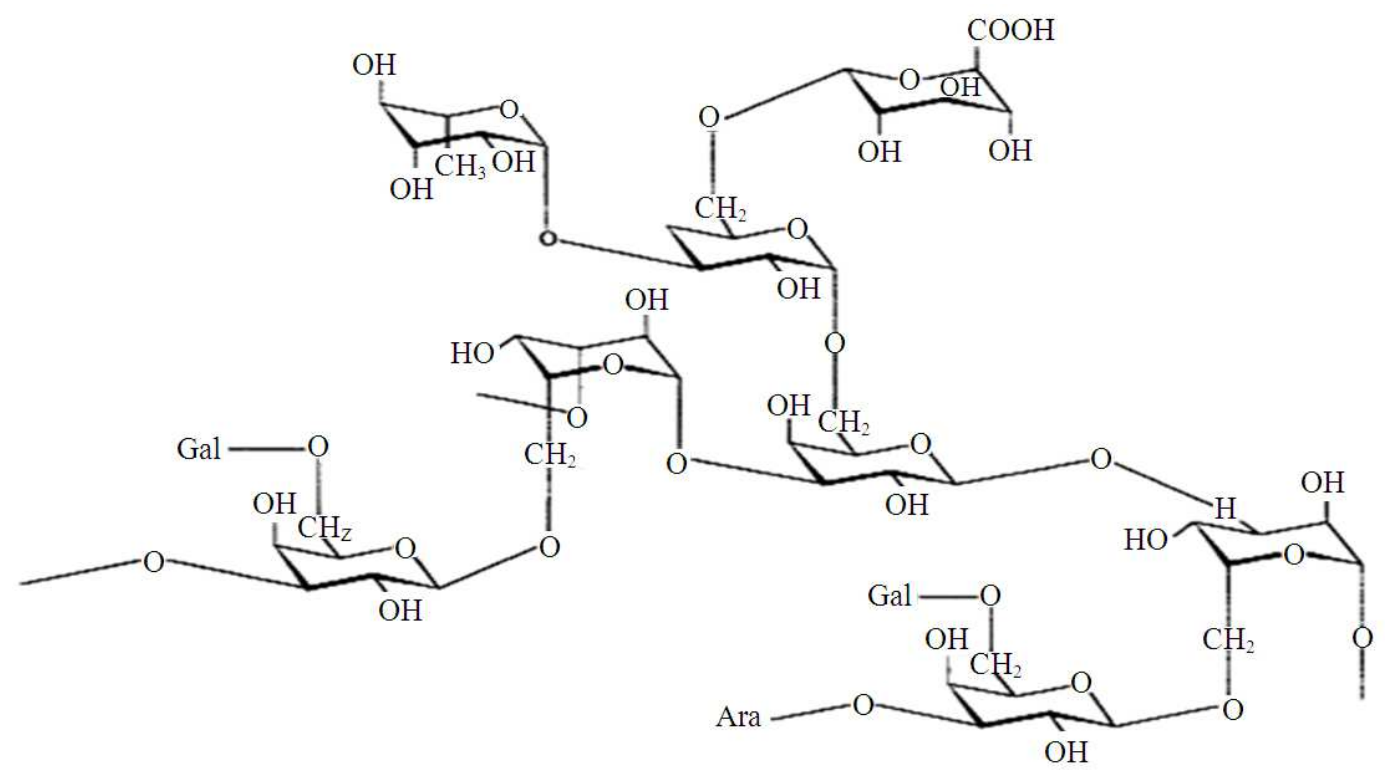

Fig. 2. Structure of Gum Arabic

- A smaller fraction is a higher molecular weight arabinogalactan-protein complex (GAGP-GA glycoprotein) in which arabinogalactan chains are covalently linked to a protein chain through serine and hydroxyproline groups. The attached arabinogalactan in the complex contains glucoronic acid

- The smallest fraction having the highest protein content is a glycoprotein which differs in its amino acids composition

\subsection{Figure 2 Structure of Gum Arabic}

\subsubsection{Physical Properties of Gum Arabic}

The physical properties of gum Arabic, established as quality parameters include moisture, total ash, volatile matter and internal energy. Gum Arabic is a natural product complex mixture of hydrophilic carbohydrate and hydrophobic protein components emulsifier which adsorbs onto surface of oil droplets while hydrophilic carbohydrate component inhibits flocculation and coalescence of molecules through electrostatic and steric repulsions in food additives (Lelon et al., 2010). Table 1 shows the international specification of quality parameters of gum Arabic.

Moisture content facilitates the solubility of hydrophilic carbohydrates and hydrophobic proteins in gum Arabic. Total ash content is used to determine the critical levels of foreign matter, acid insoluble matter, salts of calcium, potassium and magnesium. The cationic compositions of ash content are used to determine the specific levels of heavy metals in gum Arabic (Lelon et al., 2010).

\subsection{Characteristics of Gum Arabic}

Gum Arabic is a solid of a pale to orange brown colour which, when ruptured, secretes a vitreous substance. Gum Arabic of excellent quality is tearshaped, round, with an orange-brown colour. After it is crushed or shattered, the pieces are paler in colour and have a vitreous appearance. Contrary to other vegetable gums, gum Arabic dissolves very well in water (up to $50 \%)$. The viscosity of $A$. Senegal is weak $(16 \mathrm{ml} / \mathrm{g}$ on average). The resulting solution is colourless, tasteless and does not interact easily with other chemical compounds (ITC, 2008).

Chemically, gum Arabic is a slightly acidic complex compound, made up of glycoprotein and polysaccharides and their calcium, magnesium and potassium salts. The principal polysaccharide is Arabic acid, a polysaccharide linking a D-galactose with branches composed of Larabinose, L-rhamnose and D-glucuronic acids. Essentially, the proteins are classified as arabinogalactanes, rich in hydroxproline. Figure 3 shows pieces of raw gum Arabic. The photos are intended to display the shape, texture and transparency of gum Arabic (Badreldin et al., 2008).

Table 2 shows the different characteristics of gum A. senegal and A. seyal. Relatively, A. senegal contains higher in galactose, rhamnose and glucuronic acid than A. Seyal. 


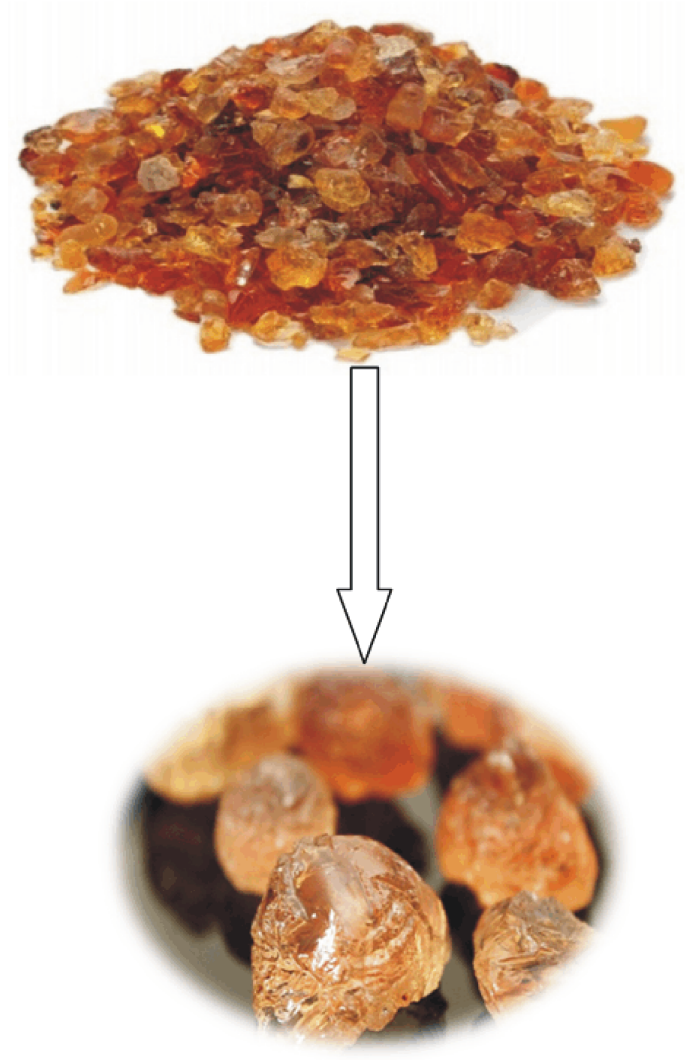

Fig. 3. Pieces of raw Gum Arabic

Table 1. International specifications of quality parameters of gum Arabic

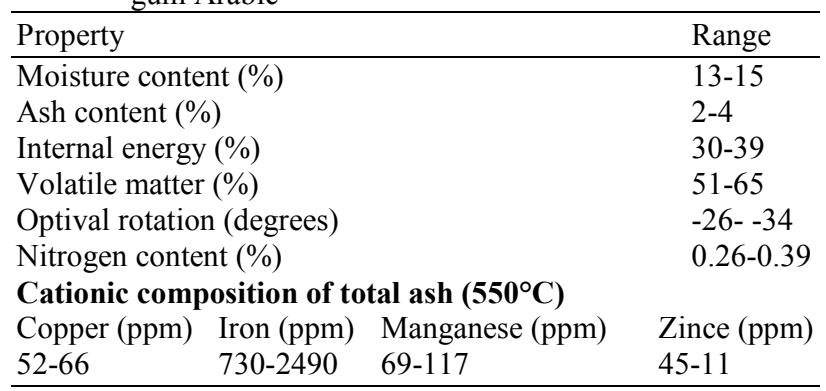

Table 2. Characteristics of gum from a. sengal and a. seyal

\begin{tabular}{lll}
\hline & Acacia senegal & Acacia seyal \\
\hline \% galactose & 44.00 & 38.00 \\
$\%$ arabinose & 27.00 & 46.00 \\
$\%$ rhamnose & 13.00 & 4.00 \\
\% glucuronic acid & 14.50 & 6.50 \\
4-O-meth1 glucuronic acid & 1.50 & 5.50 \\
\% nitrogen & 0.36 & 0.15 \\
Specific rotation/degrees & -30.00 & 51.00 \\
Average molecular mass (mw) & 380,000 & 850,000 \\
\hline
\end{tabular}

\subsection{Description of Acacia Species which Produce Gum Arabic: Acacia Senegal}

Family:

Mimosaceous

Legumes

(Leguminosae-Mimosoideae)

Synonyms:

Acacia vérek Guill et Perrott; Mimosa senegal L. (1753), Acacia rupestris Stokes.

Vernacular names: White gum tree, Verek (French); Gum Arabic tree, gum tree, three thorned acacia (English); Kittir (Arab). Figure 4 shows the gum Arabic from $A$. Senegal tree.

\subsection{Distribution of Acacia Senegal}

A tree typical of Sahel climates, A. senegal is widespread in the dry regions of tropical Africa, from Senegal and Mauritania, in the west, up to Eritrea and Ethiopia in the north-east and down to South Africa, in the south. Of the four renowned varieties, A. senegal is the most widespread and is found in all the regions where as $A$. senegal trees are located, along the West coast of central and southern Africa (Eisa et al., 2008).

Outside Africa, it is also found in Oman, Pakistan and India and has also been introduced in Egypt, Australia, Puerto Rico and the Virgin Islands. This variety is the main source of gum Arabic. Other varieties, such as var. kerensis Schweinf may be found in Ethiopia, Somalia, Uganda, Kenya and Tanzania; var. leiorhachis Brenan in all of East Africa, from Ethiopia to South Africa; var. rostrata (Sim) Brenan is also found in the same region as well as in Namibia and Angola and potentially Oman, as well (Eisa et al., 2008).

\subsection{Characteristics of Acacia Senegal}

Acacia senegal is a shrub or tree of small to medium size measuring up to $15 \mathrm{~m}$ in height, prickly and deciduous. The bark may be yellowish brown to crimson black in colour, rough or smooth, have a papyrus consistency and may be peeled apart in strips or heavily cracked and black in older trees. The treetop may be slightly rounded, flat and somewhat spread out or even spindly and frayed with branches of irregular sizes. The tree may have small, smooth branches or be 'hairy' in texture with small goads appearing in sets of three, right under the knots, where the central goad points downwards and the lateral ones towards the top; at times there are no lateral goads and the immature goads change colour from a reddish colour to a black colour (Eisa et al., 2008). 


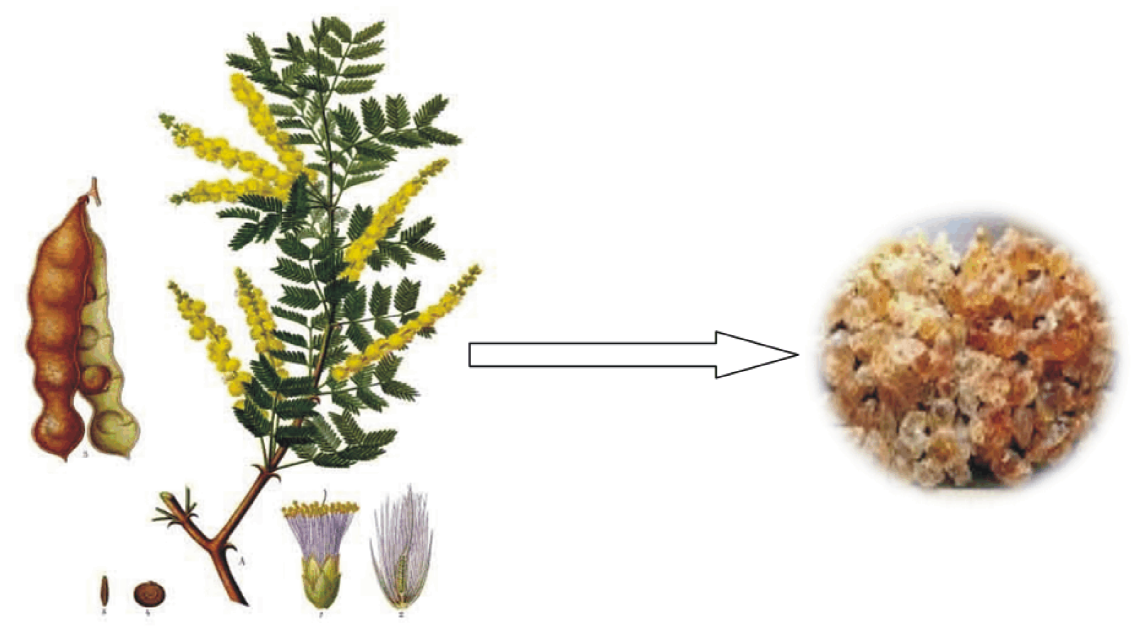

Fig. 4. The gum Arabic from Acacia Senegal tree

Family:

Mimosaceous

(Leguminosae-Mimosoideae)

Legumes

Synonyms:

Acacia stenocarpa Hochst; Acacia hockii De Wild.

Vernacular names:Mimosa épineux (French); Talha (Arabe). Figure 5 shows the gum Arabic from A. Seyal tree.

\subsection{Acacia Seyal}

\subsubsection{Characteristics of Acacia Seyal}

Acacia seyal is a small to medium tree (up to $17 \mathrm{~m}$ high and $60 \mathrm{~cm}$ in diameter) with a distinct sunshade shape for the treetop in adult trees. The bark is a pale green-gray colour or a rusty red for the seyal variety due to an underlying layer of a brightly coloured green powder. On old trees, the bark is grey-black in colour and made up of corrugated layers. The bark of the fistula variety is white or greenish-yellow in colour (Mohammed and Rohle, 2011). The branches are bright red in colour and secrete a yellowish gum, as do cracks and slits in the bark resulting from dryness. The small branches also have numerous reddish small glands and auxiliary thorns organized in pairs. The latter are $7 \mathrm{~cm}$ long, slender, straight, pointy and light gray in colour (Mohammed and Rohle, 2011).

\subsection{Distribution of Acacia Seyal}

A tree typical of semi-arid African regions, the seyal variety is the most widespread stretching throughout the Sahel from Senegal, through Sudan, Egypt, Ethiopia and down through East Africa, up to Tanzania. The fistula variety is confined in the horn of Africa, central and east Africa (Mohammed and Rohle, 2011; Eisa et al., 2008). Normally found in areas with 500-1200 mm rain/yr and a distinct dry season. The upper elevation limit is about $2000 \mathrm{~m}$. Lowest temperature within its natural range is $5-10^{\circ} \mathrm{C}$ occasionally below $5^{\circ} \mathrm{C}$ at high altitudes but the pattern of distribution indicates a frost-sensitive species. Grows well on deep, heavy soils with high $\mathrm{pH}$ (6-8) and especially var. fistula is tolerant to water logging (DFSC, 2000).

\subsection{Applications of Gum Arabic}

Exudate gums are used in an overwhelming number of applications, mainly situated in the food area. However, there are also considerable non-food applications. Gum Arabic is being widely used for industrial purposes such as a stabilizer, a thickener, an emulsifier and an encapsulating in the food industry and to a lesser extent in textiles, ceramics, lithography, cosmetic and pharmaceutical industry. In the food industry, GA is primarily used in confectionery, bakery, dairy, beverage and as a microencapsulating agent (Mariana et al., 2012).

Gum Arabic readily dissolves in cold and hot water in concentrations up to $50 \%$. Because of the compact, branched structure and therefore small hydrodynamic volume, gum Arabic solutions are characterized by a low viscosity, allowing the use of high gum concentrations in various applications. Solutions exhibit Newtonian behavior at concentrations up to $40 \%$ and become pseudoplastic at higher concentrations (Verbeken et al., 2003). 


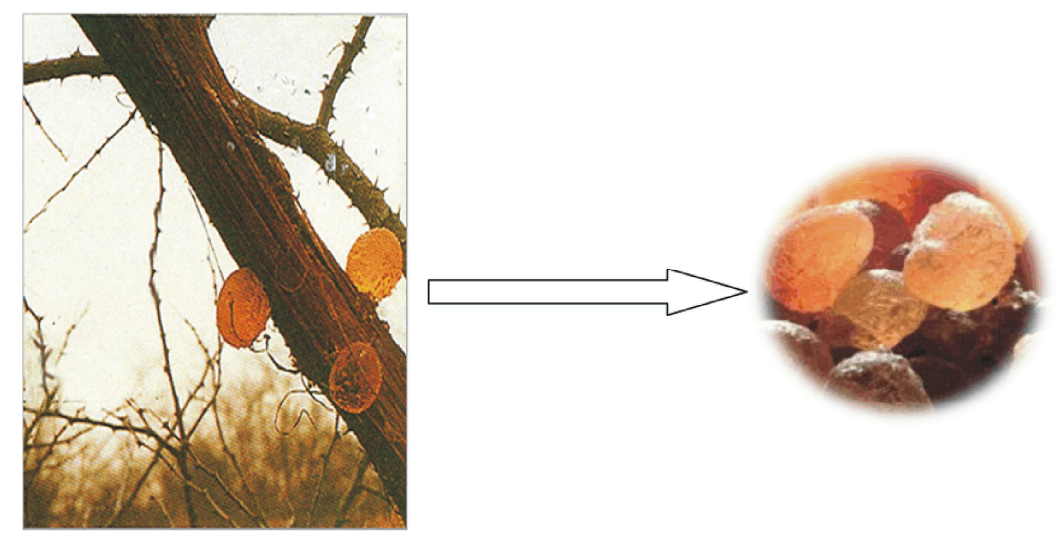

Fig. 5. The gum Arabic from A. Seyal tree

The $\mathrm{pH}$ of the solutions is normally around 4.5-5.5, but maximal viscosity is found at $\mathrm{pH}$ 6.0. Gum Arabic has excellent emulsifying properties. The hydrophobic polypeptide backbone strongly adsorbs at the oil-water interface, while the attached carbohydrate units stabilize the emulsion by steric and electrostatic repulsion. Fractionation studies show that, although emulsifying properties generally improve with increasing molecular weight and protein content, the best results are obtained with mixtures of different fractions. Seemingly, the heterogeneous nature of the gum makes it an excellent emulsifier (Verbeken et al., 2003).

\subsection{Food Applications}

Gum Arabic is mainly used in the confectionery industry, where it is incorporated in a wide range of products. It has a long tradition of use in wine gums, where it produces a clarity that is higher than can be obtained with other hydrocolloids. Furthermore, it prevents sucrose crystallization, provides a controlled flavor release and slows down melting in the mouth, making the wine gum long lasting. It also provides the appropriate texture to these candies, which are easily deformed in the mouth but do not adhere to the teeth (Arja et al., 2011).

In lower-calorie candy, gum Arabic is used to compensate for the loss of texture, mouthfeel and body, resulting from the replacement of sugars by artificial sweeteners. It is also used in chewing gum as a coating agent and as a pigment stabilizer. In aerated confectionery products, such as marshmallows, nougats and meringues, gum Arabic acts as a whipping and stabilizing agent. It is also used in toffees and caramels as an emulsifier, to maintain a uniform distribution of the fat across the product. In jelly products, it is used to provide a fibrous, fruit-like texture (Tadesse et al., 2007).

Gum Arabic is widely used as an emulsifier in the manufacture of soft drinks. Due to its stability in acid conditions and its high solubility, gum Arabic is well suited for use in citrus and cola flavor oil emulsions. High levels of gum are used to ensure a complete coverage of the interface and to prevent flocculation and coalescence of oil droplets. Normally, a weighting agent is added to increase the oil-phase density, inhibiting destabilization due to creaming (Wyasu and Okereke, 2012).

Gum Arabic can also form a stable cloud in the drink, imitating the effect of added fruit pulps and juices. Gum Arabic is used increasingly as a source of soluble fiber in low-calorie and dietetic beverages. In powdered beverage mixes, gum Arabic is added to produce the same opacity, appearance, mouth feel and palatability as natural fruit juices (Wyasu and Okereke, 2012).

In microencapsulation, liquid, solid or gaseous substances are coated with a protective layer to prevent chemical deterioration and the loss of volatile compounds. It is a useful technique to convert liquid food flavors to flowable powders that can be used in dry food products. Gum Arabic is an effective encapsulation agent because of its high water solubility, low viscosity and emulsification properties and is used in soups and dessert mixes. Gum Arabic is also used to prevent gelation in canned gravy based pet foods, as it inhibits the extraction of proteins from the meat into the gravy (Verbeken et al., 2003). Figure 6 shows applications food of gum Arabic, such as: Meat products, dairy products, bakery products, beverage, confectionery and flavors.

\subsection{Non-Food Applications}

Gum Arabic was once extensively used in the pharmaceutical industry, but is now replaced by celluloses and modified starches in many applications. It is still used as a suspending agent, emulsifier, adhesive and binder in tabletting and in demulcent syrups. 


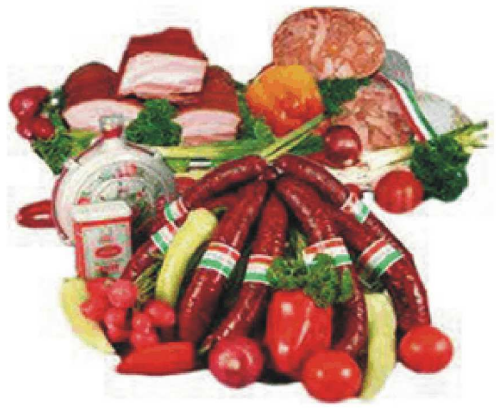

Meat products

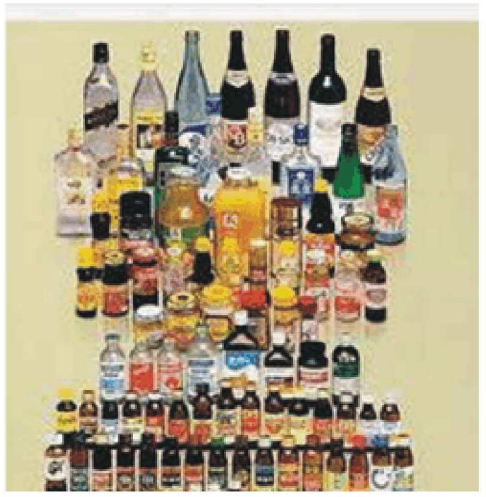

Beverage

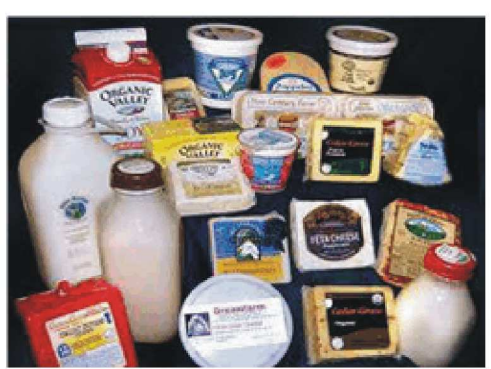

Dairy products

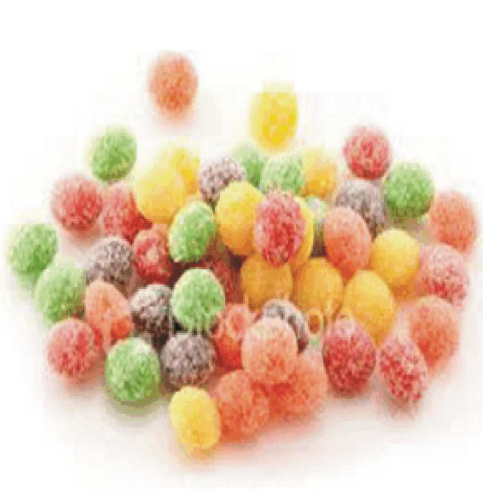

Confectionery

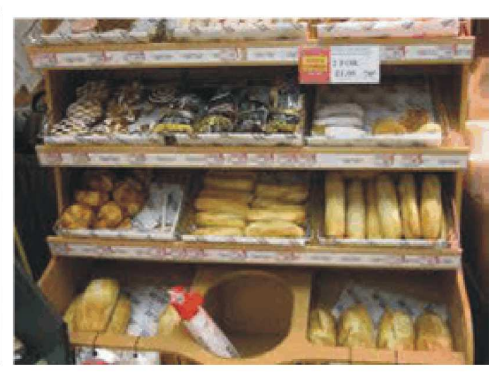

Bakery products

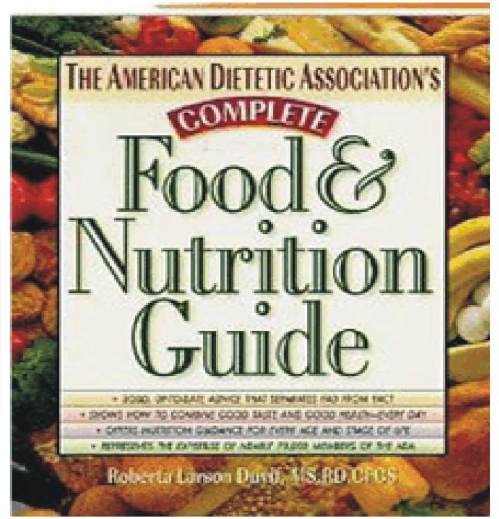

Low calorie

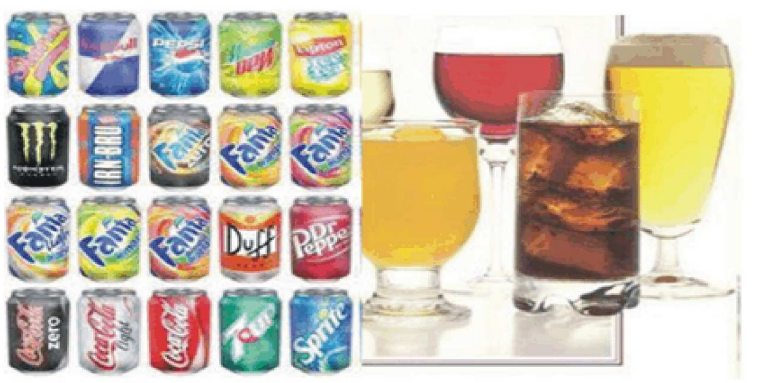

Flavours

Fig. 6. Applications food of gum Arabic

In cosmetics, gum Arabic functions as a stabilizer in lotions and protective creams, where it increases viscosity, imparts spreading properties and provides a protective coating and a smooth feel. It is used as an adhesive agent in blusher and as a foam stabilizer in liquid soaps (Arja et al., 2011).

Gum Arabic is also used in the preparation of etching and plating solutions in the lithography industry. It is used as a dispersant in paints and insecticidal/acaricidal emulsions, respectively keeping the pigments and active components uniformly distributed throughout the product. In the textile industry, it is used as a thickening agent in printing pastes for the coloration of knitted cellulose fabrics. Other applications are ink and pigment manufacture, ceramics and polishes (Verbeken et al., 2003). Figure 7 non-applications food of gum Arabic, such as: Ink, glue, paint, cosmetics, pharmaceutical and Textile. 


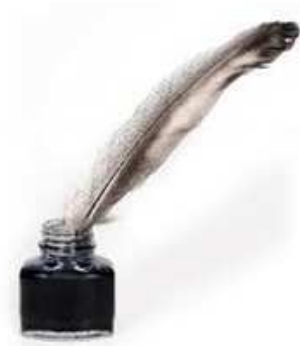

Ink

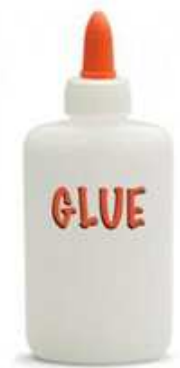

Glue

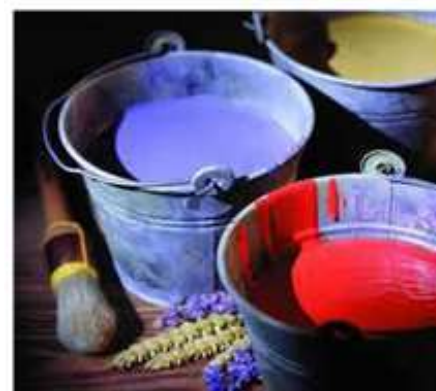

Paint

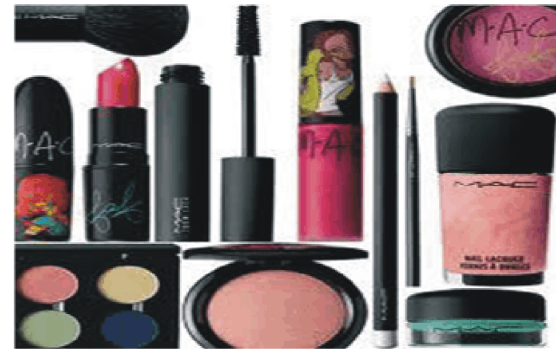

Cosmetics

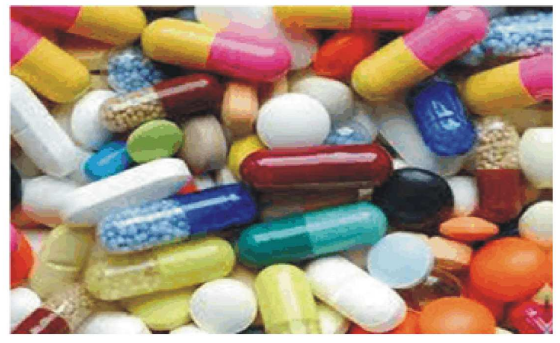

Pharmaceutical

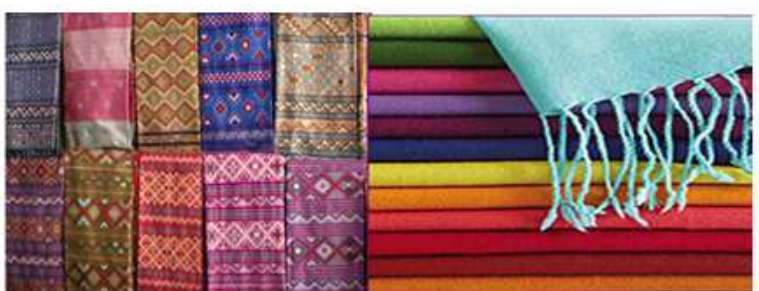

Textile

Fig. 7. Non-applications Food of gum Arabic

\subsection{Uses of Gum Arabic}

Gum Arabic has several domestic uses namely in manufacturing ink, making adhesives, crafts making, in cosmetic products, in confectionary and in foodstuff. It is also utilized locally in special meals and as chewing gum. Focusing specifically on human consumption, gum Arabic is an excellent dietary product because it contains less than 1cal for every gram. The Hottentots in southern Africa can survive for several days on nothing but gums, while Moorish populations in northern Africa sustain a daily portion of $170 \mathrm{~g}$ of gum (Arja et al., 2011).

Ever since the pharaonic era, gum has been utilized in traditional medicine as a calming and softening agent.
It is equally included in (traditional) medicine concoctions to address internal ailments such as cough, diarrhea, dysentery and hemorrhage and applied externally. It is also used in veterinary medicine, to treat skin diseases and inflammations for example. Table 3 showed the amino acid content in gum arabic obtained from A. senegal (Mariana et al., 2012). The Ebers manuscript (a medical document on papyrus written around $1550 \mathrm{BC}$ ) describes acacia gum or GA as a means of contraception when utilized with dates. Nevertheless, gum Arabic is most famous and prized by producing and exporting countries for its industrial uses, among others, in the nutrition, pharmaceutical and cosmetic branches (Verbeken et al., 2003). 
Table 3. Amino acid content in gum Arabic obtained from $A$.

\begin{tabular}{|c|c|c|}
\hline Aminoacid & $(\mathrm{nmol} / \mathrm{mg}) \mathrm{GA}$ & $\%$ Aminoacid \\
\hline Hydroxyproline & 54.200 & 0.711 \\
\hline Serine & 28.700 & 0.302 \\
\hline Threonene & 15.900 & 0.208 \\
\hline Proline & 15.600 & 0.180 \\
\hline Leucine & 15.100 & 0.198 \\
\hline Histidine & 10.700 & 0.166 \\
\hline Aspartic acid & 10.600 & 0.141 \\
\hline Glutamic acid & 8.290 & 0.122 \\
\hline Valine & 7.290 & 0.085 \\
\hline Phenylalanine & 6.330 & 0.105 \\
\hline Lysine & 5.130 & 0.075 \\
\hline Alanine & 5.070 & 0.045 \\
\hline Isoleucine & 2.380 & 0.031 \\
\hline Tyrosine & 2.300 & 0.042 \\
\hline Arginine & 2.120 & 0.037 \\
\hline Methionine & 0.110 & 0.002 \\
\hline Cysteine & 0.000 & 0.000 \\
\hline Tryptophan & 0.000 & 0.000 \\
\hline
\end{tabular}

Source: (Mariana et al., 2012)

Gum Arabic is utilized in the food industry to set flavors, as an emulsifying agent, to prevent the crystallization of sugar in confectionary and as a stabilizing agent in frozen dairy products. It is also useful in the baking industry because of its viscous and adhesive properties, which are used to stabilize mousses and as a turbidity agent in beer. Gum Arabic is a soluble alimentary fiber, a property that allows it to be functional in the body, as have been demonstrated by several studies. In fact, alimentary fibers are described as the remains of vegetable cells which the intestine does not digest and are capable of diffusing into the large intestine and fermenting when it contact of micro flora therein. Most compounds, which fit the above description, are polysaccharides of the (plant cells) inner membrane (ITC, 2008).

Gum Arabic is composed primarily of highly branched galactane polymers with side chains of galactose and/or arabinose, ending eventually in residues of rhamnose or glucorinic acid. The human digestive system does not secrete nor create enzymes capable of hydrolyzing this polysaccharide. Therefore, gum Arabic travels through the stomach and small intestine without getting digested and only when in the large intestine does it undergo fermentation induced by surrounding bacteria. Gum Arabic is completely fermented because no detectable amounts are excreted with the faeces. It is broken down and excreted as gas during respiration or absorbed by the mucus layer in the form of short fatty acids (Arja et al., 2011; ITC, 2008; Verbeken et al., 2003).
Gum Arabic is utilized to stabilize emulsions, as a binding agent and for coating medications. It is also included in the mixtures for eye drops and cough syrups. In the cosmetic field, it is used as an adhesive when making face powders and masks but also used in making lotions creamy and smooth. In the chemical industry, gum Arabic is utilized as glue, as a colloid protector and as a preserving agent for inks. It is also used to sensitize lithographic plates, to stiffen cloth, coat certain paper types and for coating metals to prevent corrosion. It is equally utilized in manufacturing matchsticks and ceramics (ITC, 2008).

Other areas where gum Arabic is used are pharmaceuticals and the printing industry. The use of gum Arabic in non-food use has been estimated to grow about 4\% (on volume basis) between 1988 and 1995. In food products, gum Arabic is used as a functional ingredient, which means that the typical functions of GA are: Emulsifier, flavoring agent, humectants, thickener, surface-finishing agent and retards sugar crystallization (Azeez, 2005). In addition, gum Arabic has water solubility, is insoluble in alcohols and forms colourless, tasteless solutions. The food applications of GA have been developed from its unequalled combination of properties. Emulsification, acid stability, low viscosity at high concentration, adhesive and binding properties and good mouth feel characteristics have been applied in five main food areas worldwide in descending order of importance which includes: Confectionary, beverages and emulsions, flavor encapsulation, bakery products and brewing (Azeez, 2005).

\section{CONCLUSION}

Gum Arabic is mostly used in the different sectors of the food. It is a non-digestible food ingredient that has many applications in the food and pharmaceutical industries.

\section{ACKNOWLEDGEMENT}

This study was funded by UKMGUP-NBT-27-103 and UKM OUP-NBT-29-139/2011.

\section{REFERENCES}

Abd-Razig, N.M., M.K. Sabahelkhier and O.F. Idris, 2010. Effect of gum Arabic (Acacia senegal, L. Willd) on lipid profile and performance of laying hens. J. Applied Biosci., 32: 2002-2007. 
Abdul-Hadi, A.H., A.E. Mahmoud and H.M. AbdelWahab, 2010. Effect of gum Arabic on coagulation system of albino rats. Int. J. Pharm. Tech. Res., 2: 1762-1766.

Arja, V., S. Maija and L. Kaija, 2011. Gum Arabic as a cause of occupational allergy. J. Allergy. DOI: $10.1155 / 2011 / 841508$

Azeez, O.S., 2005. Decolourization of gum Arabic using activated charcoal. Leonardo J. Sci., 7: 23-32.

Badreldin, H.A., Z. Amal and B. Gerald, 2008. Biological effects of gum Arabic: A review of some recent research. Food Chem. Toxicol., 47: 1-8. DOI: 10.1016/j.fct.2008.07.001

DFSC, 2000. Acica seyal del. Danida Forest Seed Centre.

Eisa, M.A., M. Roth and G. Sama, 2008. Acacia senegal (Gum Arabic Tree): Present role and need for future conservation/Sudan. Deutscher Tropentag.

Forestry Department, 1995. Exudate gums, gum Arabic: Gum talah and other acaia gums. FAO Corporate Document Repository.

ITC, 2008. Gum Arabic. Market News Service (MNS), Quarterly Edition.

Lelon, J.K., I.O. Jumba, J.K. Keter, C. Wekesa and F.D.O. Oduor, 2010. Assessment of physical properties of gum Arabic from Acacia senegal varieties in Baringo District, Kenya. Afr. J. Plant Sci., 4: 95-98.
Mariana, A.M., L.B. María, V. Lorena and D.B. Claudio, 2012. Gum Arabic: More than an edible emulsifier. Products Applic. Biopolymers. DOI: 10.5772/33783

Mohammed, M.H. and H. Rohle, 2011. Evaluation of Height functions for Acacia seyal Del. natural stands, South Kordofan Sudan. Int. J. Sustain. Agric., 3: 88-96.

Nasir, O., A. Ferruh, S. Amal, M.A. Kambal and K. Hubert et al., 2008. Effects of gum Arabic (Acacia senegal on water and electrolyte balance in healthy mice. J. Renal Nutr., 18: 230-238.

Tadesse, W., G., Desalegn and R., Alia, 2007. Natural gum and resin bearing species of Ethiopia and their potential applications. Instituto Nacional de Investigación y Tecnología Agraria y Alimentaria, 16: 211-221.

Verbeken, D., S. Dierckx and K. Dewettinck, 2003. Exudate gums: Occurrence, production and applications. Applied Microbiol. Biotechnol., 63: 10-21. DOI 10.1007/s00253-003-1354-z

Wyasu, G. and N.Z.J. Okereke, 2012. Improving the film forming ability of gum Arabic. J. Nat. Prod. Plant Resour, 2: 314-317.

Yael, D., C. Yachin and Y. Rachel, 2006. Structure of gum Arabic in aqueous solution. J. Polymer Sci., 44: 3265-3271. DOI: $10.1002 /$ polb. 20970 